\title{
Reduction of non-esterified fatty acids improves insulin sensitivity and lowers oxidative stress, but fails to restore oxidative capacity in type 2 diabetes: a randomised clinical trial
}

\author{
Esther Phielix • Tomas Jelenik • Peter Nowotny • \\ Julia Szendroedi • Michael Roden
}

Received: 28 July 2013 / Accepted: 11 November 2013 /Published online: 6 December 2013

(C) Springer-Verlag Berlin Heidelberg 2013

\begin{abstract}
Aims/hypothesis Muscle mitochondrial function can vary during fasting, but is lower during hyperinsulinaemia in insulinresistant humans. Ageing and hyperlipidaemia may be the culprits, but the mechanisms remain unclear. We hypothesised that (1) insulin would fail to increase mitochondrial oxidative capacity in non-diabetic insulin-resistant young obese humans and in elderly patients with type 2 diabetes and (2) reducing NEFA levels would improve insulin sensitivity by raising oxidative capacity and lowering oxidative stress.

Methods Before and after insulin (4, 40, $100 \mathrm{nmol} / \mathrm{l})$ stimulation, mitochondrial oxidative capacity was measured in permeabilised fibres and isolated mitochondria using highresolution respirometry, and $\mathrm{H}_{2} \mathrm{O}_{2}$ production was assessed fluorimetrically. Tissue-specific insulin sensitivity was measured with hyperinsulinaemic-euglycaemic clamps combined with stable isotopes. To test the second hypothesis, in a 1-day randomised, crossover study, 15 patients with type 2 diabetes recruited via local advertisement were assessed for eligibility. Nine patients fulfilled the inclusion criteria (BMI $<35 \mathrm{~kg} / \mathrm{m}^{2}$;
\end{abstract}

Electronic supplementary material The online version of this article (doi:10.1007/s00125-013-3127-2) contains peer-reviewed but unedited supplementary material, which is available to authorised users.

E. Phielix $\cdot$ T. Jelenik $\cdot$ P. Nowotny $\cdot$ J. Szendroedi $\cdot$ M. Roden $(\square)$

Institute for Clinical Diabetology, German Diabetes Center,

Leibniz Center for Diabetes Research, Auf'm Hennekamp 65, 40225 Düsseldorf, Germany

e-mail: michael.roden@ddz.uni-duesseldorf.de

J. Szendroedi $\cdot$ M. Roden

Department of Endocrinology and Diabetology,

Heinrich-Heine University, Düsseldorf, Germany

J. Szendroedi $\cdot$ M. Roden

German Center for Diabetes Research, Düsseldorf, Germany age $<65$ years) and were allocated to and completed the intervention, including oral administration of $750 \mathrm{mg}$ placebo or acipimox. Blinded randomisation was performed by the pharmacy; all participants, researchers performing the measurements and those assessing study outcomes were blinded. The main outcome measures were insulin sensitivity, oxidative capacity and oxidative stress.

Results Insulin sensitivity and mitochondrial oxidative capacity were $\sim 31 \%$ and $\sim 21 \%$ lower in the obese groups than in the lean group. The obese participants also exhibited blunted substrate oxidation upon insulin stimulation. In the patients with type 2 diabetes, acipimox improved insulin sensitivity by $\sim 27 \%$ and reduced $\mathrm{H}_{2} \mathrm{O}_{2}$ production by $\sim 45 \%$, but did not improve basal or insulin-stimulated mitochondrial oxidative capacity. No harmful treatment side effects occurred.

Conclusions/interpretation Decreased mitochondrial oxidative capacity can also occur independently of age in insulinresistant young obese humans. Insulin resistance is present at the muscle mitochondrial level, and is not affected by reducing circulating NEFAs in type 2 diabetes. Thus, impaired plasticity of mitochondrial function is an intrinsic phenomenon that probably occurs independently of lipotoxicity and reduced glucose uptake.

Trial registration Clinical Trials NCT00943059

Funding This study was funded in part by a grant from the German Federal Ministry of Education and Research to the German Center for Diabetes Research (DZD e.V.).

Keywords Energy metabolism $\cdot$ Hydrogen peroxide $\cdot$ Insulin resistance $\cdot$ Obesity $\cdot$ Type 2 diabetes
Abbreviations
EGP Endogenous glucose output
ETC Electron transport chain
fATP Flux through ATP synthase 


$\begin{array}{ll}\text { FCCP } & \begin{array}{l}\text { Carbonyl cyanide p-[trifluoromethoxyl]-phenyl- } \\ \text { hydrozone }\end{array} \\ \text { FDR } & \text { First-degree relatives } \\ \text { GOX } & \text { Glucose oxidation } \\ \text { LOX } & \text { Lipid oxidation } \\ \text { NS } & \text { Non-significant } \\ R_{\mathrm{a}} & \text { Rate of glucose appearance } \\ \text { RCT } & \text { Randomised controlled trial } \\ R_{\mathrm{d}} & \text { Rate of glucose disappearance } \\ \text { ROS } & \text { Reactive oxygen species } \\ \text { TCA } & \text { Tricarboxylic acid }\end{array}$

\section{Introduction}

During the last decade, several studies have revealed compromised in vivo and ex vivo mitochondrial function in patients with type 2 diabetes mellitus and/or in first-degree relatives (FDRs) [1-4]. Other studies, however, did not find abnormal in vivo mitochondrial function at baseline in patients with type 2 diabetes [5-7]. Despite this inconsistency of results, studies agree on the presence of a blunted stimulatory effect of insulin on mitochondrial ATP synthetic flux measured in vivo in patients with type 2 diabetes [7, 8].

Intravenous insulin infusion stimulates in vivo unidirectional flux through muscle ATP synthase (fATP) $[7,9,10]$ as well as ex vivo maximal ATP production rate in non-diabetic humans $[11,12]$, indicating that insulin stimulates maximal mitochondrial oxidative capacity. This effect seems to be blunted or absent in patients with type 2 diabetes [7, 12], FDRs [8] and patients with type 1 diabetes [9]. Insulin has been shown to increase specific phosphorylation sites of ATP synthase by $\sim 50 \%$ in lean and healthy, but not insulinresistant, individuals [13]. Some investigators suggest that the insulin-resistant state may limit glucose uptake or substrate oxidation or reduce substrate transport into mitochondria during hyperinsulinaemia $[11,12]$. Reduced substrate transport results in diminished production of tricarboxylic acid (TCA) cycle intermediates and lower production of NADH and $\mathrm{FADH}_{2}$, which drives mitochondrial oxygen consumption and ATP synthesis. In line with this, patients with type 2 diabetes have lower resting ATP turnover than non-diabetic humans [7]. To overcome the possibility of limited muscle glucose transport despite hyperinsulinaemic conditions in patients with type 2 diabetes, the effect of insulin on fATP was also measured under hyperglycaemic conditions to match the insulin-induced increase in intramyocellular glucose 6-phosphate observed in non-diabetic humans [7]. Interestingly, even hyperglycaemia did not restore the stimulatory effect of insulin on fATP in these patients, suggesting intrinsic mitochondrial abnormalities as previously suggested $[2,3,14]$.
Hyperglycaemia, lipotoxicity and/or ageing may be the underlying causes of the blunted stimulatory effect of insulin $[10,15]$. However, it is unclear whether young, insulinresistant humans without a family history of type 2 diabetes also exhibit a blunted insulin-stimulated increase in mitochondrial oxidative capacity.

We aimed to elucidate whether (1) insulin fails to increase mitochondrial oxidative capacity in an insulin-resistant state independently of age, diabetes and substrate availability, and (2) reducing NEFA levels improves insulin sensitivity by raising mitochondrial oxidative capacity and lowering oxidative stress. To this end, we measured in vivo insulin sensitivity, ex vivo mitochondrial oxidative capacity and $\mathrm{H}_{2} \mathrm{O}_{2}$ production before and/or during short-term lowering of NEFAs by acipimox. We furthermore investigated ex vivo mitochondrial oxidative capacity before and after stimulation by insulin.

\section{Methods}

Study participants Fifteen (eleven male/four female) obese patients with type 2 diabetes and twelve (six male/six female) obese non-diabetic and 15 (twelve male/three female) lean nondiabetic humans were included in a registered clinical trial (ClinicalTrial.gov registration no. NCT01229059) (Table 1). The institutional ethics board approved the study, for which all participants gave their written informed consent. All participants had a stable body weight and sedentary lifestyle and no clinical or biochemical evidence of cardiac, hepatic or renal diseases or diabetes-related complications. Non-diabetic participants had no family history of type 2 diabetes and normal glucose tolerance according to a standard $75 \mathrm{~g}$ OGTT. Patients had well-controlled type 2 diabetes with known diabetes duration of 1.5-10 years and treatment with metformin only or metformin + sulfonylurea. They were older than the obese and lean non-diabetic participants (Table 1).

Hyperinsulinaemic-euglycaemic clamp After an overnight fast, a two-step hyperinsulinaemic-euglycaemic clamp (lowdose insulin at $10 \mathrm{mU} \mathrm{m}^{-2} \mathrm{~min}^{-1}$ for $4 \mathrm{~h} \mathrm{[16],} \mathrm{followed} \mathrm{by}$ high-dose insulin at $40 \mathrm{mU} \mathrm{m}^{-2} \mathrm{~min}^{-1}$ for $2.5 \mathrm{~h} \mathrm{[10])} \mathrm{com-}$ bined with $\mathrm{D}-\left[6,6{ }^{2} \mathrm{H}_{2}\right]$ glucose was performed to measure whole-body insulin-stimulated glucose appearance rate $\left(R_{\mathrm{a}}\right)$, glucose disposal rate $\left(R_{\mathrm{d}}\right)$ and endogenous glucose production (EGP) [17] at plasma glucose levels of $5.0 \mathrm{mmol} / 1$ ( $90 \mathrm{mg} / \mathrm{dl})$. At baseline and clamp steady state, indirect calorimetry was performed to measure substrate oxidation [18] with postcalorimetric correction of metabolic monitor variability [19]. At least 1 week before the clamp test, patients with type 2 diabetes stopped their glucose-lowering medication. Three days before the clamp, all participants were instructed to avoid physical activity, to maintain normal dietary habits during the study period, and to consume carbohydrate-rich meals three 
Table 1 Participants' characteristics
Data are mean \pm SD

$* p<0.05 \mathrm{~T} 2 \mathrm{DM}$ vs lean

${ }^{\dagger} p<0.05$ obese vs lean

${ }^{\ddagger} p<0.05$ T2DM vs obese

T2DM, patients with type

2 diabetes; TG, triacylglycerol;

GPT, glutamate-pyruvate amino-

transferase (also known as alanine aminotransferase); GGT,

$\gamma$-glutamyltransferase; AST,

aspartate aminotransferase

\begin{tabular}{|c|c|c|c|}
\hline Characteristic & T2DM & Obese & Lean \\
\hline $\operatorname{Sex}(m / f)$ & $15(11 / 4)$ & $12(6 / 6)$ & $15(12 / 3)$ \\
\hline Age (years) & $56.9 \pm 9.0^{*}$ & $30.8 \pm 6.9$ & $26.3 \pm 4.9$ \\
\hline Weight (kg) & $101.9 \pm 15.1^{*} \star \star$ & $132.0 \pm 27.6^{\dagger}$ & $75.6 \pm 12.6$ \\
\hline BMI $\left(\mathrm{kg} / \mathrm{m}^{2}\right)$ & $34.6 \pm 4.2^{*} \star$ & $41.4 \pm 7.0^{\dagger}$ & $23.8 \pm 2.4$ \\
\hline Fat mass (kg) & $40.5 \pm 12.8^{*}$ & $59.3 \pm 23.5^{\dagger}$ & $16.3 \pm 5.3$ \\
\hline Fat-free mass $(\mathrm{kg})$ & $62.8 \pm 14.9$ & $72.7 \pm 16.5^{\dagger}$ & $58.4 \pm 10.1$ \\
\hline Fat $(\%)$ & $39.3 \pm 11.2 *$ & $41.6 \pm 6.8^{\dagger}$ & $21.7 \pm 5.4$ \\
\hline Fasting insulin $(\mathrm{pmol} / \mathrm{l})$ & $151.4 \pm 65.3^{*}$ & $144.5 \pm 50.7^{\dagger}$ & $77.1 \pm 34.0$ \\
\hline Fasting glucose (mmol/l) & $8.2 \pm 3.8^{*}+$ & $4.5 \pm 0.6$ & $4.4 \pm 0.4$ \\
\hline Fasting TG $(\mathrm{mmol} / \mathrm{l})$ & $209.0 \pm 73.7^{*}$ 屯 & $136.0 \pm 78.1^{\dagger}$ & $99.7 \pm 55.4$ \\
\hline Fasting HDL-cholesterol (mmol/l) & $43.5 \pm 16.6^{*}$ & $43.5 \pm 10.5^{\dagger}$ & $59.8 \pm 20.1$ \\
\hline Fasting LDL-cholesterol (mmol/l) & $134.8 \pm 32.0 *$ & $129.4 \pm 32.8$ & $110.2 \pm 25.1$ \\
\hline GPT (U/l) & $41.7 \pm 27.5^{*}$ & $39.1 \pm 17.1^{\dagger}$ & $26.0 \pm 10.5$ \\
\hline GGT (U/l) & $49.5 \pm 22.5^{*}, 末$ & $28.1 \pm 17.8$ & $28.6 \pm 23.4$ \\
\hline AST (U/l) & $27.3 \pm 9.7$ & $27.3 \pm 6.8$ & $25.3 \pm 4.9$ \\
\hline Creatinine $(\mu \mathrm{mol} / \mathrm{l})$ & $79.6 \pm 17.7$ & $70.7 \pm 17.7$ & $79.6 \pm 17.7$ \\
\hline $\mathrm{HbA}_{1 \mathrm{c}}(\%)$ & $7.3 \pm 1.9^{*}, \star$ & $5.3 \pm 0.3$ & $5.1 \pm 0.3$ \\
\hline $\mathrm{HbA}_{1 \mathrm{c}}(\mathrm{mmol} / \mathrm{mol})$ & $69 \pm 21^{*}, \star$ & $34 \pm 3$ & $32 \pm 3$ \\
\hline
\end{tabular}

times a day. At $3 \mathrm{~h}$ before the start of the clamp and immediately after the end of the clamp, muscle biopsy samples were taken from the vastus lateralis muscle under local anaesthesia (2\% lidocaine) [20].

Lipid-lowering intervention Fifteen patients with type 2 diabetes (13 male/two female) were recruited from January 2011 to August 2012 for this registered randomised clinical trial (RCT) (ClinicalTrial.gov registration no. NCT00943059) Four patients with clinical diabetes-related comorbidities such as cardiovascular diseases, diabetic foot, polyneuropathy and retinopathy were excluded. In addition, one patient declined to participate (electronic supplementary material [ESM] Fig. 1). On the basis of the inclusion criteria $\left(\mathrm{BMI}<35 \mathrm{~kg} / \mathrm{m}^{2}\right.$; age $<65$ years), nine patients (seven male/two female) were enrolled in this double-blinded crossover RCT to test the effects of lowering plasma NEFAs. They stopped taking their regular glucose-lowering medication for 1 week and then ingested acipimox or placebo (250 $\mathrm{mg}$ three times a day) for 1 day at home. Participants were provided with sequentially numbered containers with either placebo or verum manufactured by the pharmacy (University Medical Center, St Radboud, Nijmegen, the Netherlands). On the morning of the next day, another dose of acipimox $(250 \mathrm{mg})$ was administered at the German Diabetes Center, and a muscle biopsy specimen was taken $1 \mathrm{~h}$ later. Five patients underwent hyperinsulinaemic-euglycaemic clamps before the intervention (baseline), after 1 day of acipimox, as well as after placebo treatment. All data were collected at the research institute. The primary outcome variable was mitochondrial oxidative capacity. The secondary outcome variables were whole-body insulin sensitivity and reactive oxygen species (ROS). All nine patients completed the study.

Ex vivo insulin stimulation Muscle samples ( 15 mg) were immediately transferred to the preservation medium, BIOPS, containing $\mathrm{CaK}_{2}$ EGTA (2.8 mmol/l), $\mathrm{K}_{2}$ EGTA (7.2 mmol/l), $\mathrm{Na}_{2}$ ATP $(5.8 \mathrm{mmol} / \mathrm{l}), \mathrm{MgCl}_{2} \quad 6 \mathrm{H}_{2} \mathrm{O}(6.6 \mathrm{mmol} / \mathrm{l})$, taurine (20 mmol/l), disodium phosphocreatine $(15 \mathrm{mmol} / \mathrm{l})$, imidazole (20 mmol/1), dithiothreitol and 4-morpholine-ethanesulfonic acid $(50 \mathrm{mmol} / \mathrm{l})$. Muscle samples were incubated in the presence of different concentrations of insulin $(0,4,40$ and $100 \mathrm{nmol} / \mathrm{l}$ ) in the preservation medium for $2.5 \mathrm{~h}$, then permeabilised using saponin, and rinsed using respiration medium as described previously $[2,3,21]$.

High-resolution respirometry Ex vivo analysis of mitochondrial oxidative capacity was performed on permeabilised muscle fibres and isolated mitochondria in a two-chamber oxygraph (OROBOROS Instruments, Innsbruck, Austria) as described previously [21]. In permeabilised muscle fibres, maximal oxidative phosphorylation (State 3) and uncoupled respiration (State $u$ ) were quantified in the presence of malate $(2.0 \mathrm{mmol} / \mathrm{l})$, pyruvate $(5.0 \mathrm{mmol} / \mathrm{l})$, ADP $(1.0 \mathrm{mmol} / \mathrm{l})$, glutamate $(10.0 \mathrm{mmol} / \mathrm{l})$ and succinate $(10.0 \mathrm{mmol} / \mathrm{l})$. Then, cytochrome $c(10 \mu \mathrm{mol} / \mathrm{l})$ was added to test the integrity of the outer mitochondrial membrane, followed by incremental titration steps of $1.0 \mu$ carbonyl cyanide $\mathrm{p}$-[trifluoromethoxyl]phenyl-hydrozone (FCCP) $(0.1 \mathrm{mmol} / \mathrm{l})$ until maximal uncoupled respiration was achieved. This experiment was also 
performed in the absence of pyruvate. In a different protocol, fatty acid oxidation was analysed by subsequent addition of malate $(2.0 \mathrm{mmol} / \mathrm{l})$, octanoyl-carnitine $(50 \mu \mathrm{mol} / \mathrm{l})$, ADP $(1.0 \mathrm{mmol} / \mathrm{l})$, glutamate $(10 \mathrm{mmol} / \mathrm{l})$, succinate $(10 \mathrm{mmol} / \mathrm{l})$ and cytochrome $c(10 \mu \mathrm{mol} / \mathrm{l})$, and followed by incremental titration $(1.0 \mu \mathrm{l})$ of FCCP until maximal uncoupled respiration. Oxygen consumption was corrected for muscle wet mass $(2-4 \mathrm{mg})$ and given as oxygen flux expressed as pmol mg $\mathrm{g}^{-1} \mathrm{~s}^{-1}$.

In isolated mitochondria, we carried out a respiratory experiment similar to that performed in permeabilised fibres, including malate $(2.0 \mathrm{mmol} / \mathrm{l})$, glutamate $(10 \mathrm{mmol} / \mathrm{l})$, ADP $(1.0 \mathrm{mmol} / \mathrm{l})$, succinate $(10 \mathrm{mmol} / \mathrm{l})$, cytochrome $c(10 \mu \mathrm{mol} / \mathrm{l})$ and titrations $(1.0 \mu \mathrm{l})$ with FCCP. Also, experiments were performed using sequential addition of malate $(2.0 \mathrm{mmol} / \mathrm{l})$, pyruvate $(5.0 \mathrm{mmol} / \mathrm{l})$, ADP $(1.0 \mathrm{mmol} / \mathrm{l})$ and oligomycin $(2 \mu \mathrm{g} / \mathrm{ml})$ and subsequent incremental titration of FCCP $(1.0 \mu \mathrm{l})$. This setup was also used in the presence of octanoyl-carnitine $(50 \mu \mathrm{mol} / \mathrm{l})$ instead of pyruvate.

Isolation of mitochondria Muscle tissue (250-300 mg) was used to isolate mitochondria according to a previously described protocol [22]. In short, the muscle tissue was transferred to a mitochondrial isolation buffer containing sucrose $(100 \mathrm{mmol} / \mathrm{l}), \mathrm{KCl}(100 \mathrm{mmol} / \mathrm{l}), \mathrm{TRIS} / \mathrm{HCl}(50 \mathrm{mmol} / \mathrm{l})$, $\mathrm{KH}_{2} \mathrm{PO}_{4}(1 \mathrm{mmol} / \mathrm{l})$, EGTA $(0.1 \mathrm{mmol} / \mathrm{l})$ and fatty acid-free albumin from bovine serum $(1.0 \mathrm{~g} / 500 \mathrm{ml}$ isolation buffer). The muscle tissue was cut into small pieces with sharp scissors, treated with proteinase (Nagarse, $0.2 \mathrm{mg} / \mathrm{ml}$ ) and homogenised. An aliquot of $100 \mu \mathrm{l}$ was stored at $-80^{\circ} \mathrm{C}$ for later protein determination. Differential high-speed centrifugation yielded a mitochondrial pellet, which was resuspended in isolation buffer and stored on ice for high-resolution respirometry and fluorescence Amplex Red measurement. Protein content of the mitochondrial suspension was measured fluorimetrically with Fluram $(300 \mu \mathrm{g} / \mathrm{ml}$ acetone $)$.

$\mathrm{H}_{2} \mathrm{O}_{2}$ production An aliquot of $0.1 \mathrm{mg}$ isolated mitochondria was used to measure rates of $\mathrm{H}_{2} \mathrm{O}_{2}$ production fluorimetrically by the Amplex Red method as described elsewhere [23]. Briefly, the emitted $\mathrm{H}_{2} \mathrm{O}_{2}$ was selectively trapped by horseradish peroxidase, which uses Amplex Red as an electron donor during the reduction of $\mathrm{H}_{2} \mathrm{O}_{2}$ to $\mathrm{H}_{2} \mathrm{O}$. The resulting fluorescent product, resorufin, was continuously monitored with a SPEX Fluoromax 3 spectrofluorimeter (Horiba Jobin Yvon, Longjumeau, France) at $37^{\circ} \mathrm{C}$ and magnetic stirring at more than $1,000 \mathrm{rpm}$. The production of $\mathrm{H}_{2} \mathrm{O}_{2}$ was measured indirectly under succinate-supported State 4 respiration $(10 \mu \mathrm{g} / \mathrm{ml}$ oligomycin), in the presence of malate $(2.0 \mu \mathrm{mol} / \mathrm{l})$ and glutamate $(5.0 \mu \mathrm{mol} / \mathrm{l})$. Succinate was added in increasing concentrations ranging from 0.05 to $1.5 \mathrm{mmol} / \mathrm{l}$, followed by the addition of rotenone $(0.1 \mu \mathrm{mol} / \mathrm{l})$, to inhibit $\mathrm{H}_{2} \mathrm{O}_{2}$ production from complex I, and antimycin A $(2.5 \mu \mathrm{mol} / \mathrm{l})$, to induce maximal $\mathrm{H}_{2} \mathrm{O}_{2}$ production via the inhibition of complex III.
Analytical measurements Plasma glucose was assessed using the glucose oxidase method (Beckman, Fullerton, CA, USA), NEFA was measured microfluorimetrically (Wako Chemicals, Richmond, VA, USA), and plasma insulin and C-peptide were determined radioimmunometrically (Pharmacia, Uppsala, Sweden) [10]. All other blood variables assessed were analysed in routine laboratory procedures.

Calculations and statistics Steel's single-pool steady-state equations were used to calculate baseline and insulin-stimulated glucose $R_{\mathrm{a}}$ and $R_{\mathrm{d}}$ [17]. EGP was calculated as $R_{\mathrm{a}}$ minus exogenous glucose infusion rate. Whole-body carbohydrate and fat oxidation rates were calculated using stoichiometric equations of Frayn [18]. Metabolic flexibility was expressed as the change in insulin-stimulated increase in RQ. The change in insulinstimulated glucose oxidation (GOX) was calculated as GOX during the $40 \mathrm{mU}$ insulin clamp minus GOX at baseline. The change in insulin-suppressed lipid oxidation (LOX) was calculated as LOX at baseline minus LOX during the $40 \mathrm{mU}$ clamp. From the Amplex Red method, $\mathrm{H}_{2} \mathrm{O}_{2}$ production during the backflux of electrons from complex II to complex I was calculated by subtracting rotenone-inhibited $\mathrm{H}_{2} \mathrm{O}_{2}$ production from $\mathrm{H}_{2} \mathrm{O}_{2}$ production during succinate-induced State 4 respiration and expressed as a percentage. All data are reported as mean \pm SEM. Statistical analyses were performed using the statistics program SPP 18.0 for Mac OS X. Differences between the three groups were tested by one-way ANOVA and post hoc Bonferroni correction for multiple testing. Differences within groups in the different insulin-stimulated oxygen fluxes were tested using ANOVA for repeated measurements and post hoc Bonferroni correction. The sample size of this RCT was computed on values reported for mitochondrial function analysis as published previously [3]. Differences were considered significant at $p<0.05$.

\section{Results}

Cross-sectional comparison Whole-body insulin sensitivity was equally reduced in obese non-diabetic humans and patients with type 2 diabetes compared with lean humans $(p<0.05$, Fig. 1a, Table 2$)$. The change in whole-body insulin-stimulated GOX was similar in obese participants and patients with type 2 diabetes, but lower than in the lean group ( $p<0.05$, Table 2$)$. Also, the change in insulinsuppressed LOX was similar in obese humans and patients with type 2 diabetes and lower than in the lean group $(p<0.05$, Table 2). Metabolic flexibility did not differ between the three groups ( $p=$ non-significant (NS) Table 2).

State 3 respiration (in the presence of ADP) on glutamate, as well as on glutamate + succinate (in the presence of ADP), was also lower in skeletal muscle of the obese non-diabetic participants and patients with type 2 diabetes than in the lean 

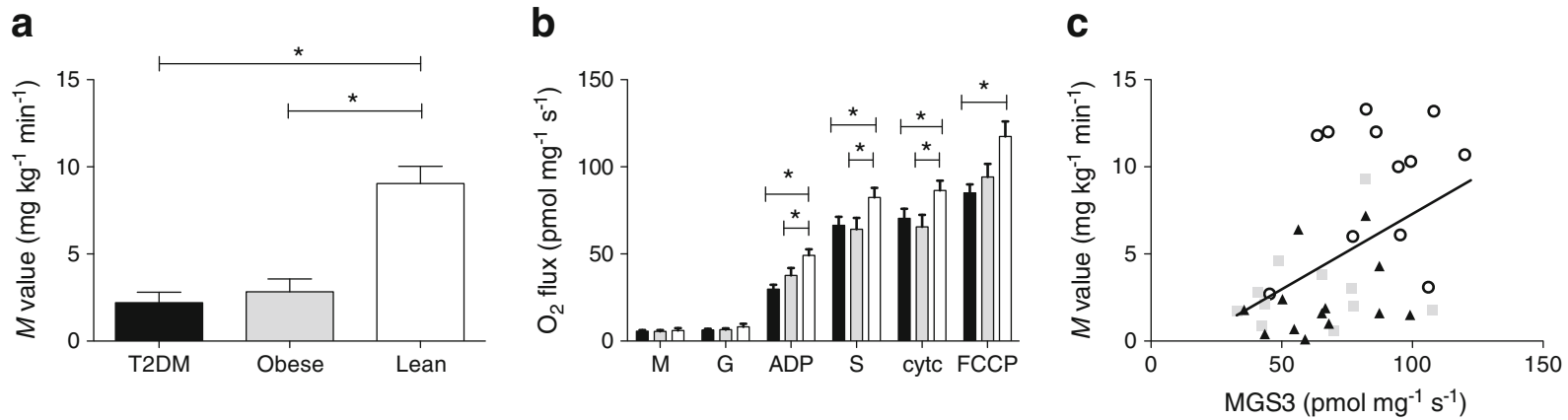

Fig. 1 (a) Whole-body insulin sensitivity ( $M$ value) in lean and obese participants and patients with type 2 diabetes (T2DM). (b) Mitochondrial oxidative capacity $\left(\mathrm{O}_{2}\right.$ flux $)$ measured in permeabilised muscle fibres in lean (white bars) and obese (grey bars) participants and patients with T2DM (black bars). Oxidative capacity was measured by the sequential addition of malate (M), glutamate (G), ADP, succinate (S), cytochrome $c$ (cytc) and step-wise titration of FCCP. State 3 indicates the oxidative capacity using a specific substrate in the presence of ADP, thereby coupling substrate oxidation to ATP production. (c) Correlation $\left(r^{2}=0.22, p<0.01\right)$ between whole-body insulin sensitivity ( $M$ value) and State 3 respiration on malate + glutamate + succinate (MGS3) across lean (circles), obese (squares) and T2DM participants (triangles). Data are expressed as mean $\pm \mathrm{SEM} ; * p<0.05$ participants (State 3 respiration on glutamate, 22\% and 39\% $[p<$ 0.05], respectively; State 3 respiration on glutamate + succinate, $22 \%$ and $20 \%[p<0.05]$, respectively) (Fig. 1b). The addition of cytochrome $c$ gave similar respiratory values to those seen on State 3 respiration on glutamate + succinate, which indicates that the outer mitochondrial membrane remained intact in these experiments. State $u$ respiration was lower in both obese groups compared with the lean group $(20 \%$ and $28 \%[p<0.05]$ for obese non-diabetic participants and patients with type 2 diabetes, respectively vs lean) (Fig. 1b).

Across all groups, insulin sensitivity correlated positively with State 3 respiration on glutamate + succinate $\left(r^{2}=0.22\right.$,

Table 2 Whole-body substrate kinetics

\begin{tabular}{lccr}
\hline & T2DM & Obese & \multicolumn{1}{l}{ Lean } \\
\hline$M$ value $\left(\mathrm{mg} \mathrm{kg}^{-1} \mathrm{~min}^{-1}\right)$ & & & \\
$\quad$ Clamp & $2.2 \pm 0.6^{*}$ & $2.8 \pm 0.7^{\dagger}$ & $9.0 \pm 1.0$ \\
GOX $\left(\mu \mathrm{mol} \mathrm{kg}{ }^{-1} \mathrm{~min}^{-1}\right)$ & & & \\
$\quad$ Basal & $5.4 \pm 1.5$ & $7.4 \pm 1.7$ & $6.7 \pm 1.5$ \\
Clamp & $10.6 \pm 1.1^{*}$ & $10.3 \pm 1.2^{\dagger}$ & $20.0 \pm 1.9$ \\
Change $\left(\mathrm{GOX}_{\text {clamp }}-\mathrm{GOX}_{\text {basal }}\right)$ & $5.6 \pm 1.3^{*}$ & $4.7 \pm 1.7^{\dagger}$ & $14.2 \pm 2.4$ \\
LOX $\left(\mu \mathrm{mol} \mathrm{kg} \mathrm{min}^{-1}\right)$ & & & \\
Basal & $1.1 \pm 0.2$ & $0.8 \pm 0.2^{\dagger}$ & $1.4 \pm 0.1$ \\
Clamp & $0.4 \pm 0.1$ & $0.4 \pm 0.1$ & $0.5 \pm 0.1$ \\
Change $\left(\mathrm{LOX}_{\text {clamp }}-\mathrm{LOX}_{\text {basal }}\right)$ & $-0.5 \pm 0.1^{*}$ & $-0.5 \pm 0.1^{\dagger}$ & $-1.0 \pm 0.2$ \\
RQ & & & \\
Basal & $0.79 \pm 0.02$ & $0.81 \pm 0.02$ & $0.77 \pm 0.01$ \\
Clamp & $0.88 \pm 0.02$ & $0.90 \pm 0.02$ & $0.93 \pm 0.02$ \\
Change $\left(\mathrm{RQ}_{\text {clamp }}-\mathrm{RQ}_{\text {basal }}\right)$ & $0.09 \pm 0.02$ & $0.09 \pm 0.03$ & $0.15 \pm 0.03$ \\
\hline
\end{tabular}

Data are mean \pm SEM

${ }^{*} p<0.05$ between patients with type 2 diabetes (T2DM) and lean humans ${ }^{\dagger} p<0.05$ between obese and lean humans $p<0.05$; Fig. 1c). No correlation was found within the groups $\left(r^{2}=0.04,0.05\right.$ and 0.07 for lean, obese and type 2 diabetes $[p=\mathrm{NS}]$, respectively). Neither was a correlation found between insulin sensitivity and plasma NEFAs, nor with changes in insulin-stimulated mitochondrial oxidative capacity.

Ex vivo insulin stimulation (4, 40 and $100 \mathrm{nmol} / \mathrm{l})$ of muscle fibres of lean humans increased State 3 respiration by $13 \%, 28 \%$ and $24 \%$ ( $p<0.05$ for all) on pyruvate + glutamate and by $13 \%, 23 \%$ and $18 \%(p<0.05$ for 4 and $40 \mathrm{nmol} / \mathrm{l}$ insulin, respectively, with a tendency for $100 \mathrm{nmol} / \mathrm{l}$ insulin $p=0.06)$ on pyruvate + glutamate + succinate and State $u$ respiration by $9 \%, 19 \%$ and $16 \%(p<0.05$ for 4 and $40 \mathrm{nmol} / 1$ insulin, respectively, with $p=0.14$ for $100 \mathrm{nmol} / 1$ insulin) (Fig. 2a). In all respiratory states, insulin exposure did not affect oxidative capacity in either obese non-diabetic participants (Fig. 2b) or patients with type 2 diabetes (Fig. 2c).

Lipid-lowering intervention In patients with type 2 diabetes, plasma glucose, insulin and C-peptide did not differ between baseline, placebo and verum (acipimox) treatment ( $p=\mathrm{NS}$; Table 3). Administration of acipimox resulted in rapid reduction of circulating NEFA levels during the clamp compared with baseline and placebo ( $-83 \%$ on acipimox vs both baseline and placebo, $p<0.05)$. In addition, fasting LOX decreased gradually on acipimox vs baseline $(-24 \%, p=0.05$; Fig. $3 \mathrm{a})$, but was not significantly different between acipimox and placebo $(-17 \%, p=\mathrm{NS})$.

After treatment with acipimox, whole-body insulin sensitivity was $26 \%$ and $27 \%$ higher compared with placebo and baseline ( $p<0.05$ for both; Fig. 3b). Insulin-suppressed EGP did not change between baseline, placebo and acipimox ( $38 \pm$ $10 \%, 62 \pm 17 \%$ and $50 \pm 7 \%, p=\mathrm{NS}$ ).

In permeabilised muscle fibres, neither acipimox nor placebo affected State 3 respiration on glutamate or glutamate + succinate or State $\mathrm{u}$ respiration (Fig. 3c). Likewise, 

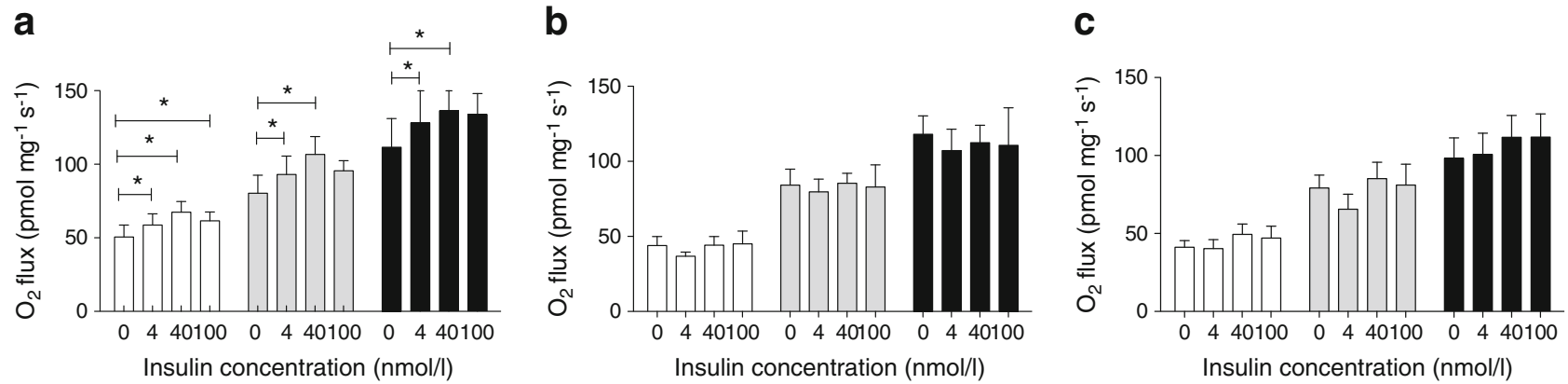

Fig. 2 Mitochondrial oxidative capacity $\left(\mathrm{O}_{2}\right.$ flux $)$ measured in permeabilised muscle fibres upon $0,4,40$ and $100 \mathrm{nmol} / 1$ insulin incubation ex vivo in lean (a) and obese (b) participants and patients with type 2 diabetes (T2DM) (c). Oxidative capacity was measured as State 3

respiration (in the presence of ADP) on malate + pyruvate + glutamate (white bars), malate + pyruvate + glutamate + succinate (grey bars) and upon the step-wise titration of FCCP (state u, black bars). Data are expressed as mean $\pm \mathrm{SEM} ;{ }^{*} p<0.05$ vs $0 \mathrm{nmol} / \mathrm{l}$ insulin

mitochondrial capacity in the presence of octanoyl-carnitine did not differ between acipimox and placebo treatment (Fig. 3d).

On acipimox treatment, respiratory capacity in isolated mitochondria tended to be lower on glutamate ( $p=0.08$; Fig. 4a), pyruvate ( $p=0.10$; Fig. $4 \mathrm{~b})$, and on State $\mathrm{u}$ respiration on pyruvate $(p=0.10 ;$ Fig. $4 \mathrm{~b})$. State 3 and State $\mathrm{u}$ respiration in the presence of octanoyl-carnitine was lower on acipimox treatment compared with placebo ( $p<0.05$ for both; Fig. $4 \mathrm{c})$. Also, oligomycin-inhibited respiration was lower on acipimox treatment, reflecting more efficient coupling between oxidative phosphorylation and ATP production $(p<0.05$; Fig. $4 \mathrm{c})$.

Acipimox treatment did not restore the insulin-stimulating effect in muscle fibres on State 3 respiration by pyruvate + glutamate (ESM Fig. 2a) or pyruvate + glutamate + succinate (ESM Fig. 2b) or for State u respiration (ESM Fig. 2c).

Maximal succinate-stimulated $\mathrm{H}_{2} \mathrm{O}_{2}$ production in isolated mitochondria did not differ between acipimox and placebo treatment (Fig. 5a). However, the presence of rotenone reduced $\mathrm{H}_{2} \mathrm{O}_{2}$ production by $39 \%$ on acipimox treatment compared with placebo ( $p<0.05$; Fig. $5 b) . \mathrm{H}_{2} \mathrm{O}_{2}$ production during the backflux of electrons from complex II to complex I did not differ between acipimox and placebo treatment ( $p=\mathrm{NS}$; Fig. 5c). Antimycin-stimulated maximal $\mathrm{H}_{2} \mathrm{O}_{2}$ production decreased by $37 \%$ on acipimox treatment compared with placebo ( $p<0.05$; Fig. 5 d).

Table 3 Circulating metabolites in patients with type 2 diabetes receiving placebo or acipimox treatment

\begin{tabular}{lccr}
\hline Metabolite & Baseline & \multicolumn{1}{l}{ PLC } & \multicolumn{1}{l}{ ACP } \\
\hline Fasting insulin (pmol/l) & $111.1 \pm 16.7$ & $118.8 \pm 11.1$ & $117.4 \pm 9.0$ \\
Fasting C-peptide (nmol/l) & $0.7 \pm 0.1$ & $0.9 \pm 0.1$ & $0.9 \pm 0.1$ \\
Fasting glucose (mmol/l) & $10.7 \pm 1.4$ & $10.7 \pm 1.0$ & $9.7 \pm 0.8$ \\
\hline
\end{tabular}

Data are mean \pm SEM

ACP, acipimox; PLC, placebo

Correlation analyses A strong positive correlation was found between the change in insulin-stimulated whole-body GOX and mitochondrial oxidative capacity, i.e. with State 3 respiration on glutamate (Fig. 6a), State 3 respiration on glutamate and succinate (Fig. 6b), as well with State u respiration (Fig. 6c). The change in insulin-stimulated GOX also correlated with insulin sensitivity (Fig. 6d). A strong correlation was found between the change in insulin-suppressed wholebody LOX and mitochondrial function, i.e. State 3 respiration on glutamate (Fig. 6e), State 3 respiration with glutamate and succinate (Fig. 6f), and State u respiration (Fig. 6g). The insulin-stimulated change in RQ correlated with State 3 respiration on glutamate (Fig. 6h). State 3 respiration on glutamate and succinate in isolated mitochondria correlated positively with maximal succinate-stimulated $\mathrm{H}_{2} \mathrm{O}_{2}$ production $\left(r^{2}=0.81, p<0.05\right.$; ESM Fig. $\left.3 \mathrm{a}\right)$ as well as with rotenone-inhibited $\mathrm{H}_{2} \mathrm{O}_{2}$ production $\left(r^{2}=0.75, p<0.05\right.$; ESM Fig. 3b). Interestingly, maximal succinate-stimulated $\mathrm{H}_{2} \mathrm{O}_{2}$ production correlated positively with $\mathrm{HbA}_{1 \mathrm{c}}$ in patients with type 2 diabetes $\left(r^{2}=0.40, p<0.05\right.$; ESM Fig. $\left.3 c\right)$. No correlation was found between plasma NEFAs and mitochondrial oxidative capacity or insulin sensitivity. No correlations were found for the metabolic variables with age.

\section{Discussion}

This study found that (1) both mitochondrial function and insulin sensitivity were similarly compromised in young, non-diabetic obese humans and patients with type 2 diabetes; (2) insulin failed to increase mitochondrial oxidative capacity in young, insulin-resistant, non-diabetic humans or elderly patients with type 2 diabetes; and (3) short-term reduction in lipid availability does not improve oxidative capacity under basal or insulin-stimulated conditions despite markedly increased insulin sensitivity and reduced production of ROS in muscle of patients with type 2 diabetes. This suggests a 

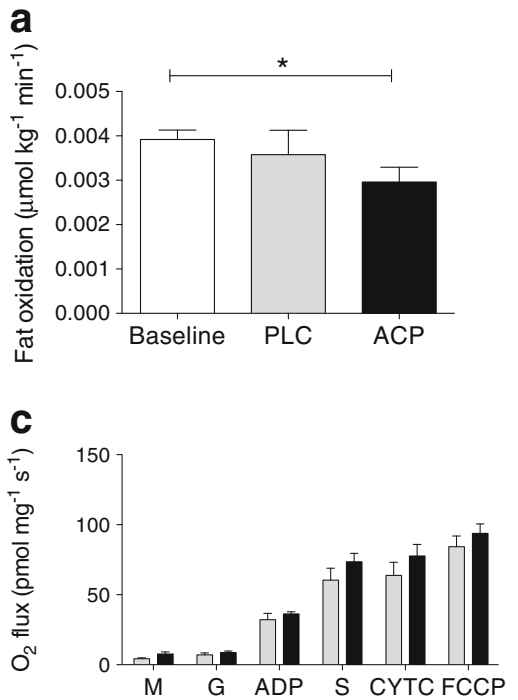

Fig. 3 Whole-body fasting fat oxidation (a) and whole-body insulinstimulated $R_{\mathrm{d}}(\mathrm{b})$ in patients with T2DM under baseline conditions (white bars) or receiving placebo (grey bars) or acipimox (black bars) treatment. Mitochondrial oxidative capacity $\left(\mathrm{O}_{2}\right.$ flux $)$ measured in permeabilised muscle fibres in patients with T2DM receiving placebo

dissociation of lipid-mediated insulin resistance and mitochondrial function.

Mitochondrial function was previously shown to be lower in patients with type 2 diabetes compared with BMI- and age-matched non-diabetic humans and in diabetic offspring $[1-3,14,24]$. In sedentary humans, insulin sensitivity and mitochondrial function gradually decline with age [10]. In the present study, mitochondrial oxidative capacity was lower in younger, but insulin-resistant, humans than in younger insulin-sensitive humans; therefore age cannot explain the observed difference in mitochondrial function. However, this cross-sectional study cannot exclude the possibility that the compromised mitochondrial oxidative capacity of these younger obese and insulin-resistant people precedes the development of type 2 diabetes in later life.

The greater oxidative capacity observed in the lean insulinsensitive participants on ex vivo insulin stimulation indicates that insulin signalling in muscle samples remains intact for $2.5 \mathrm{~h}$ of incubation in preservation medium. The ex vivo b
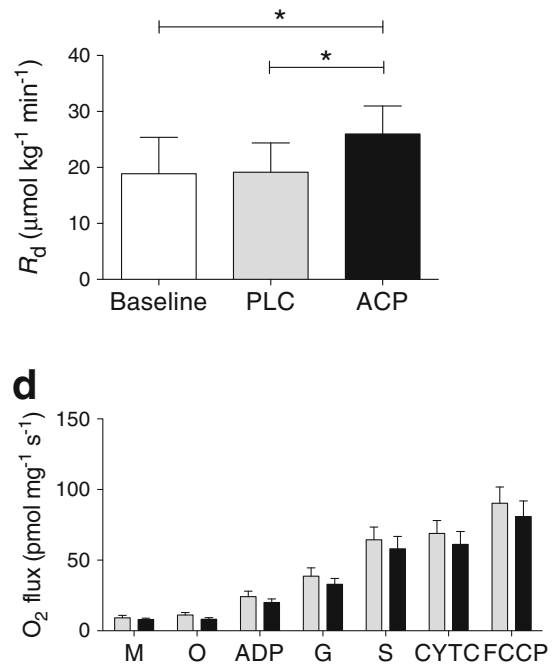

(grey bars) or acipimox (black bars) treatment in the presence of malate (M), glutamate (G), ADP, succinate (S), cytochrome $c$ (CYTC) and on step-wise titration of FCCP (c) and in the presence of octanoyl-carnitine (O) (d). Data are expressed as mean \pm SEM; ${ }^{*} p \leq 0.05$

addition of pyruvate, glutamate and succinate included testing of TCA cycle-derived intermediates downstream of the insulin-activated targets involved in glycolysis, such as hexokinase and phosphofructokinase. Therefore, the blunted insulin-stimulatory effect on mitochondrial oxidative capacity in patients with type 2 diabetes and obese insulin-resistant individuals is probably not due to alterations in insulinmediated glucose transport. As mitochondrial oxidative capacity does not increase on insulin stimulation on glutamate and succinate and is not restored on lipid lowering, mitochondrial impairment may also occur more upstream of the electron transport system. Moreover, recently, plasma and intramyocellular levels of branched-chain amino acids have been shown to be increased in insulin-resistant humans as well as in people 12 years before they developed type 2 diabetes [25], which may point to diminished oxidation of branchedchain amino acids inside the muscle. This could result in a lower entry of other TCA cycle intermediates, such as acetylCoA derived from isoleucine. Our results suggest that the
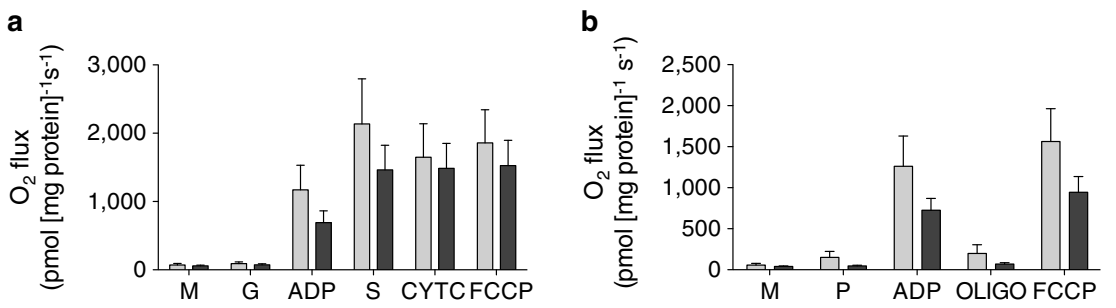

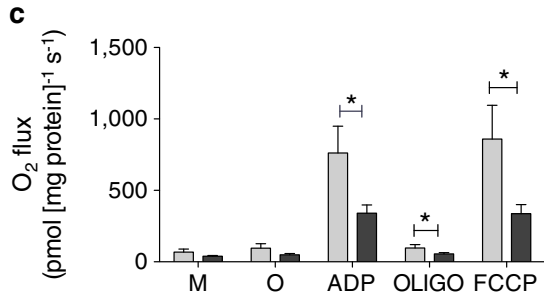

Fig. 4 Mitochondrial oxidative capacity $\left(\mathrm{O}_{2}\right.$ flux $)$ measured in isolated mitochondria in patients with T2DM on placebo (grey bar)s or acipimox (black bars) treatment using three different substrate protocols: in the presence of malate (M), glutamate (G), ADP, succinate (S), cytochrome $c$
(CYTC) and upon step-wise titration of FCCP (a); in the presence of malate $(\mathrm{M})$, pyruvate $(\mathrm{P}), \mathrm{ADP}$, oligomycin (OLIGO) and FCCP (b), or in the presence of malate $(\mathrm{M})$, octanoyl-carnitine $(\mathrm{O})$, ADP, oligomycin (OLIGO) and FCCP (c). Data are expressed as mean \pm SEM; ${ }^{*} p<0.05$ 
a

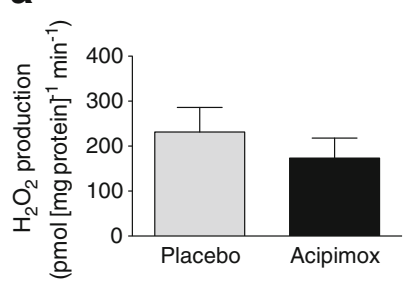

C

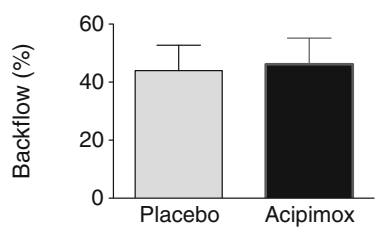

b

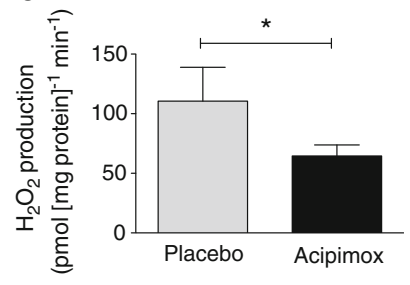

d

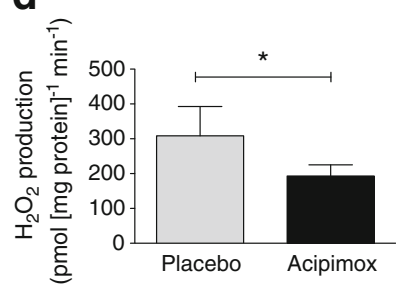

Fig. 5 Oxidative stress expressed as $\mathrm{H}_{2} \mathrm{O}_{2}$ production measured in isolated mitochondria in patients with type 2 diabetes receiving placebo or acipimox treatment using four different substrate protocols: succinatestimulated maximal $\mathrm{H}_{2} \mathrm{O}_{2}$ production in the presence of malate + glutamate (a); rotenone-inhibited $\mathrm{H}_{2} \mathrm{O}_{2}$ production in the presence of malate + glutamate + succinate (b); $\mathrm{H}_{2} \mathrm{O}_{2}$ production during backflow from complex II to complex I (c); maximal antimycin-stimulated $\mathrm{H}_{2} \mathrm{O}_{2}$ production in the presence of malate, glutamate, succinate and rotenone (d). Data are expressed as mean $\pm \mathrm{SEM} ; * p<0.05$

insulin-stimulatory effect on oxidative capacity in lean insulin-sensitive individuals results from enhanced activity of enzymes involved in oxidative phosphorylation. Insulinsensitising effects on the mitochondrial gene transcripts of cytochrome oxidase III, peroxisome proliferator-activated receptor $\gamma$ co-activator $1 \alpha$ and nuclear respiratory factor 1 have previously been reported [16]. Taking all these findings together, insulin resistance can occur at the mitochondrial level in obese patients with or without type 2 diabetes.

Despite evidence supporting the notion that augmented lipid availability underlies insulin resistance [26], subsequently reducing mitochondrial function [27], there is an ongoing discussion about whether fat accumulation, oxidative capacity and whole-body insulin sensitivity are indeed causally related. It has been postulated that myocellular fat accumulation predisposes to interaction with ROS, resulting in the formation of lipid peroxides and eventually damaging cellular structures, such as the complexes involved in mitochondrial oxidative phosphorylation [27]. Indeed, prolonged elevation of circulating NEFAs for several hours might decrease fATP even in lean healthy humans [28]. On the other hand, acute $(3 \mathrm{~h})$ reduction of lipolysis directly followed by a hyperinsulinaemic clamp did not improve fATP in patients with type 2 diabetes [29]. In the present study, mitochondrial function was evaluated on $24 \mathrm{~h}$ suppression of lipolysis under baseline conditions, i.e. without hyperinsulinaemia. The results show that sustained reduction of systemic NEFAs improves insulin sensitivity without restoring mitochondrial oxidative capacity. Thus,
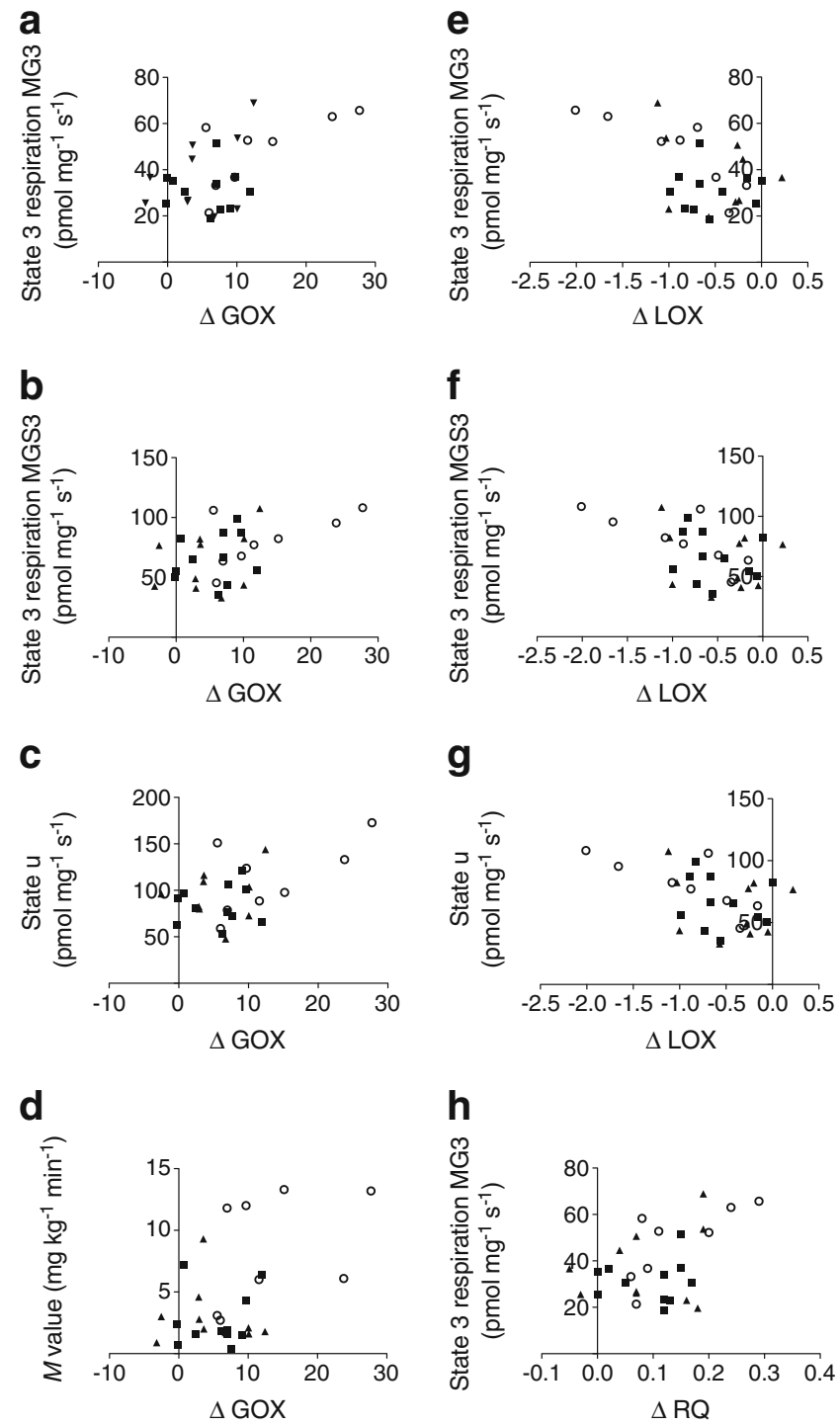

Fig. 6 Correlation of changes in insulin-stimulated whole-body GOX with State 3 respiration on glutamate $\left(\mathbf{a} ; r^{2}=0.31, p<0.01\right)$, State 3 respiration on glutamate and succinate $\left(\mathbf{b} ; r^{2}=0.23, p<0.01\right)$, State $\mathrm{u}$ respiration $\left(\mathbf{c} ; r^{2}=0.25, p<0.01\right)$ in permeabilised muscle fibres and with whole-body insulin sensitivity $\left(\mathbf{d} ; r^{2}=0.24, p<0.01\right)$. Insulin-suppressed LOX correlated with State 3 respiration on glutamate $\left(\mathbf{e} ; r^{2}=0.30\right.$, $p<0.01)$, State 3 respiration on glutamate and succinate $\left(\mathbf{f} ; r^{2}=0.23\right.$, $p<0.01)$, and State u respiration $\left(\mathbf{g} ; r^{2}=0.23, p<0.01\right)$. (h) Correlation of changes in insulin-stimulated RQ $(\Delta \mathrm{RQ})$ with State 3 respiration on glutamate $\left(r^{2}=0.20, p<0.05\right)$. Circles, lean humans; triangles, obese humans; squares, patients with type 2 diabetes; MG3, malate + glutamate; MGS3, malate + glutamate + succinate

lipotoxicity is probably not the primary cause of compromised mitochondrial function in type 2 diabetes. Of note, this does not exclude possible beneficial effects of long-term suppression of circulating NEFAs on mitochondrial function. Our study furthermore highlights that enhanced insulin sensitivity was not preceded by improved mitochondrial function. Despite the positive correlation between mitochondrial oxidative capacity and insulin sensitivity, the results suggest that insulin sensitivity and mitochondrial function are not per se 
causally related, but rather represent independent parallel features associated with type 2 diabetes.

However, lipids are known to stimulate muscle ROS production [13], which has also been implicated in insulin resistance [30] in both type 1 and type 2 diabetes [18]. In the present paper, we explore in more detail the predominant role of complex I of the electron transport chain (ETC) in lipidinduced ROS production in humans with type 2 diabetes. We also show that complex III of the ETC is pivotal in lipidinduced muscle ROS production in humans with type 2 diabetes. The decrease in ROS production was paralleled by lower fat oxidative capacity in isolated mitochondria, with a trend towards a decrease in the oxidation of pyruvate, a glycolytic intermediate. However, acipimox did not reduce fat oxidative capacity in permeabilised muscle fibres, which may be due to effects of acipimox on the present upstream dehydrogenases. In any case, the reduction in ROS production was not paralleled by restoration of insulin-stimulated mitochondrial substrate oxidation and ATP production. Thus, it remains of interest to study possible effects of a long-term sustained decrease in ROS production on mitochondrial function.

In addition to altered mitochondrial function, type 2 diabetes has been also associated with impaired metabolic flexibility, i.e. impaired switching from lipid to carbohydrate oxidation in response to insulin [31]. It is debatable whether metabolic inflexibility merely reflects insulin resistance or results from lower mitochondrial oxidative plasticity. The present study demonstrates that the changes in insulin-stimulated RQ, GOX and insulin-suppressed LOX all strongly correlate with mitochondrial oxidative capacity. This is partly in line with results of a recent paper in which in vivo mitochondrial function assessed from post-exercise phosphocreatine recovery rates predicted RQ under baseline conditions [32]. Here, we extend these findings in that ex vivo mitochondrial function, and not glucose disposal rate per se, predicts the change in insulinstimulated RQ $(\Delta R Q)$. Importantly, our results suggest that blunted insulin-suppressed LOX does not necessarily underlie insulin resistance, emphasising the absent direct causality between these two variables. The correlation of metabolic flexibility with mitochondria function, but not with insulin sensitivity, supports the contention that mitochondria are responsible for the blunted insulin-stimulated increase in substrate oxidation in insulin-resistant groups.

In conclusion, young obese insulin-resistant humans exhibit similarly low mitochondrial oxidative capacity to patients with type 2 diabetes compared with young lean humans. Furthermore, both obese groups with and without type 2 diabetes show an insulin-resistance phenomenon at the mitochondrial level, which is not reversed on short-term suppression of lipolysis. Although we have confirmed the role of lipid-induced ROS production in muscle of patients with type 2 diabetes, we have to conclude that lipotoxicity is not the main cause of the lower mitochondrial function.

Acknowledgements We would like to thank all volunteers who participated in this study. Also we thank M. Zeppetzauer and G. Sequaris for their contribution in performing respiratory measurements, both working at the German Diabetes Center at the Department of Clinical Diabetology during the conduct of this study.

Funding This study was funded in part by a grant from the German Federal Ministry of Education and Research to the German Center for Diabetes Research (DZD e.V.). EP is supported by a VENI grant (016.136.132) for innovative research from the Netherlands Organization for Scientific Research (NWO) and a grant from the European Foundation for the Study of Diabetes (EFSD). TJ is supported by an international scholarship from the German Academic Exchange Service (DAAD).

Duality of interest The authors declare that there is no duality of interest associated with this manuscript.

Contribution statement All authors contributed to the conception and design of the study, acquired, analysed and/or interpreted data, and drafted and/or revised the manuscript. All authors approved the version to be published.

\section{References}

1. Petersen KF, Dufour S, Befroy D, Garcia R, Shulman GI (2004) Impaired mitochondrial activity in the insulin-resistant offspring of patients with type 2 diabetes. N Engl J Med 350:664-671

2. Phielix E, Meex R, Moonen-Kornips E, Hesselink MK, Schrauwen P (2010) Exercise training increases mitochondrial content and ex vivo mitochondrial function similarly in patients with type 2 diabetes and in control individuals. Diabetologia 53:1714-1721

3. Phielix E, Schrauwen-Hinderling VB, Mensink M et al (2008) Lower intrinsic ADP-stimulated mitochondrial respiration underlies in vivo mitochondrial dysfunction in muscle of male type 2 diabetic patients. Diabetes 57:2943-2949

4. Schrauwen-Hinderling VB, Kooi ME, Hesselink MK et al (2007) Impaired in vivo mitochondrial function but similar intramyocellular lipid content in patients with type 2 diabetes mellitus and BMI-matched control subjects. Diabetologia 50:113-120

5. Trenell MI, Hollingsworth KG, Lim EL, Taylor R (2008) Increased daily walking improves lipid oxidation without changes in mitochondrial function in type 2 diabetes. Diabetes Care 31:1644-1649

6. De Feyter HM, van den Broek NM, Praet SF, Nicolay K, van Loon LJ, Prompers JJ (2008) Early or advanced stage type 2 diabetes is not accompanied by in vivo skeletal muscle mitochondrial dysfunction. Eur J Endocrinol 158:643-653

7. Szendroedi J, Schmid AI, Chmelik M et al (2007) Muscle mitochondrial ATP synthesis and glucose transport/phosphorylation in type 2 diabetes. PLoS Med 4:e154

8. Petersen KF, Dufour S, Shulman GI (2005) Decreased insulinstimulated ATP synthesis and phosphate transport in muscle of insulin-resistant offspring of type 2 diabetic parents. PLoS Med 2: e233

9. Kacerovsky M, Brehm A, Chmelik M et al (2011) Impaired insulin stimulation of muscular ATP production in patients with type 1 diabetes. J Intern Med 269:189-199

10. Brehm A, Krssak M, Schmid AI, Nowotny P, Waldhausl W, Roden M (2006) Increased lipid availability impairs insulin-stimulated ATP synthesis in human skeletal muscle. Diabetes 55:136-140 
11. Asmann YW, Stump CS, Short KR et al (2006) Skeletal muscle mitochondrial functions, mitochondrial DNA copy numbers, and gene transcript profiles in type 2 diabetic and nondiabetic subjects at equal levels of low or high insulin and euglycemia. Diabetes 55: 3309-3319

12. Stump CS, Short KR, Bigelow ML, Schimke JM, Nair KS (2003) Effect of insulin on human skeletal muscle mitochondrial ATP production, protein synthesis, and mRNA transcripts. Proc Natl Acad Sci U S A 100:7996-8001

13. Hojlund K, Yi Z, Lefort N et al (2010) Human ATP synthase beta is phosphorylated at multiple sites and shows abnormal phosphorylation at specific sites in insulin-resistant muscle. Diabetologia 53:541-551

14. Mogensen M, Sahlin K, Fernstrom M et al (2007) Mitochondrial respiration is decreased in skeletal muscle of patients with type 2 diabetes. Diabetes 56:1592-1599

15. Phielix E, Szendroedi J, Roden M (2011) Mitochondrial function and insulin resistance during aging: a mini-review. Gerontology 57:387-396

16. Kotronen A, Seppala-Lindroos A, Bergholm R, Yki-Jarvinen H (2008) Tissue specificity of insulin resistance in humans: fat in the liver rather than muscle is associated with features of the metabolic syndrome. Diabetologia 51:130-138

17. Steele R (1959) Influences of glucose loading and of injected insulin on hepatic glucose output. Ann N Y Acad Sci 82:420-430

18. Frayn KN (1983) Calculation of substrate oxidation rates in vivo from gaseous exchange. J Appl Physiol 55:628-634

19. Schadewaldt P, Nowotny B, Strassburger K, Kotzka J, Roden M (2013) Indirect calorimetry in humans: a postcalorimetric evaluation procedure for correction of metabolic monitor variability. Am J Clin Nutr 97:763-773

20. Bergstrom J, Hermansen L, Hultman E, Saltin B (1967) Diet, muscle glycogen and physical performance. Acta Physiol Scand 71:140-150

21. Phielix E, Meex R, Ouwens DM et al (2012) High oxidative capacity due to chronic exercise training attenuates lipid-induced insulin resistance. Diabetes 61:2472-2478
22. Tonkonogi M, Sahlin K (1997) Rate of oxidative phosphorylation in isolated mitochondria from human skeletal muscle: effect of training status. Acta Physiol Scand 161:345-353

23. Anderson EJ, Lustig ME, Boyle KE et al (2009) Mitochondrial $\mathrm{H}_{2} \mathrm{O}_{2}$ emission and cellular redox state link excess fat intake to insulin resistance in both rodents and humans. J Clin Invest 119:573-581

24. Boushel R, Gnaiger E, Schjerling P, Skovbro M, Kraunsoe R, Dela F (2007) Patients with type 2 diabetes have normal mitochondrial function in skeletal muscle. Diabetologia 50:790-796

25. Wang TJ, Larson MG, Vasan RS et al (2011) Metabolite profiles and the risk of developing diabetes. Nat Med 17:448-453

26. Itani SI, Ruderman NB, Schmieder F, Boden G (2002) Lipid-induced insulin resistance in human muscle is associated with changes in diacylglycerol, protein kinase C, and IkappaB-alpha. Diabetes 51: 2005-2011

27. Schrauwen P, Hesselink MK (2004) Oxidative capacity, lipotoxicity, and mitochondrial damage in type 2 diabetes. Diabetes 53:14121417

28. Brehm A, Krssak M, Schmid AI, Nowotny P, Waldhausl W, Roden M (2010) Acute elevation of plasma lipids does not affect ATP synthesis in human skeletal muscle. Am J Physiol Endocrinol Metab 299:E33E38

29. Lim EL, Hollingsworth KG, Smith FE, Thelwall PE, Taylor R (2011) Inhibition of lipolysis in Type 2 diabetes normalizes glucose disposal without change in muscle glycogen synthesis rates. Clin Sci (Lond) 121:169-177

30. Johannsen DL, Ravussin E (2010) Can increased muscle ROS scavenging keep older animals young and metabolically fit? Cell Metab 12:557-558

31. Phielix E, Mensink M (2008) Type 2 diabetes mellitus and skeletal muscle metabolic function. Physiol Behav 94:252-258

32. van de Weijer T, Sparks LM, Phielix E et al (2013) Relationships between mitochondrial function and metabolic flexibility in type 2 diabetes mellitus. PLoS One 8:e51648 